\title{
Effect of a 5-lipoxygenase inhibitor on leukotriene generation and airway responses after allergen challenge in asthmatic patients
}

Kok P Hui, Ian K Taylor, Graham W Taylor, Paul Rubin, James Kesterson, Neil C Barnes, Peter J Barnes

\begin{abstract}
The effect of a single oral dose $(800 \mathrm{mg})$ of zileuton (A-64077), a specific 5-lipoxygenase inhibitor, on the early and late airway responses to inhaled allergen was studied in a randomised, double blind, placebo controlled, and crossover trial in nine subjects with atopic asthma. Leukotriene generation was also assessed in vivo by measuring urinary leukotriene (LT) $E_{4}$ excretion, and ex vivo by measuring calcium ionophore stimulated whole blood LTB $_{4}$ production. Zileuton almost completely inhibited ex vivo $\mathrm{LTB}_{4}$ production but reduced urinary excretion of $\mathrm{LTE}_{4}$ by only about half. There was a trend for the early asthmatic response to be less on the day of zileuton treatment, but this did not reach statistical significance $(p=0.08)$. The zileuton induced reduction in maximum fall in $\mathrm{FEV}_{1}$ in the early asthmatic response was, however, significantly related to the reduction in urinary $\mathrm{LTE}_{4}$ excretion $(r=0.8)$, but not to the reduction in $\mathrm{LTB}_{4}$ generation ex vivo. There was no significant change in the allergen induced late asthmatic response, or in the increase in airway responsiveness to methacholine following antigen. The results provide some support for the hypothesis that the cysteinyl leukotrienes have a role in the allergen induced early asthmatic response. More complete in vivo inhibition of 5-lipoxygenase may be needed to produce a significant reduction in airway response to allergen challenge.
\end{abstract}

The leukotrienes, products of the 5-lipoxygenase pathway of arachidonic acid metabolism, are thought to be important mediators in the pathogenesis of asthma because their biological activities produce changes that are similar to those seen in asthma. ${ }^{1-3}$ The cysteinyl leukotrienes, $\mathrm{LTC}_{4}, \mathrm{LTD}_{4}$, and $\mathrm{LTE}_{4}$, are potent bronchoconstrictor agents in normal and asthmatic subjects, ${ }^{4-6}$ and $\mathrm{LTE}_{4}$ has been reported to increase airway hyperresponsiveness. ${ }^{7} \mathrm{LTB}_{4}$ is a potent chemotactic agent for leucocytes, ${ }^{8}$ and may be important in mediating the inflammatory process in asthmatic airways. $\mathrm{LTD}_{4}$ can increase mucus production in human airway preparations ${ }^{9}$ and airway microvascular leakage in animals. ${ }^{10}$ Several clinical studies with cysteinyl leukotriene antagonists in asthmatic subjects have shown a slight reduction in the early asthmatic response to inhaled allergen ${ }^{11} 12$ and in cold air induced bronchoconstriction. ${ }^{13}$ The compounds studied were relatively weak cysteinyl leukotriene antagonists, however, and they would in addition leave the effects of the dihydroxy acid $\mathrm{LTB}_{4}$ unopposed. An alternative approach is to inhibit the 5-lipoxygenase enzyme to reduce synthesis of all the leukotrienes. Several different classes of 5-lipoxygenase inhibitors have been found to be effective in animal models of asthma. ${ }^{14-16}$ No significant reduction of allergen induced bronchoconstriction was, however, proposed by piriprost $^{17}$ or nafazatrom ${ }^{18}$ in two clinical studies in man-but nafazatrom was found not to prevent ex vivo leukotriene production in man after oral dosing despite having 5-lipoxygenase inhibitory activity in vitro (the activity of piriprost in man was not studied).

After exposure to inhaled allergen there is an early and late bronchoconstrictor response in asthmatic subjects and an increase in airway responsiveness. Several mediators, including the leukotrienes, are generated during antigen challenge and may be important in mediating the airway responses. Zileuton, a hydroxamic acid 5-lipoxygenase inhibitor, ${ }^{19}$ has been shown to inhibit calcium ionophore stimulated human neutrophil production of $\mathrm{LTB}_{4}$ in man ex vivo after oral dosing, ${ }^{20}$ and is effective in inhibiting allergen induced contraction of tracheal smooth muscle in the guinea pig. ${ }^{21}$ We have investigated the efficacy of zileuton $(800 \mathrm{mg})$ on the generation of cysteinyl leukotriene in vivo (assessed by urine $\mathrm{LTE}_{4}$ concentration) induced by inhaled allergen and on the generation of $\mathrm{LTB}_{4}$ ex vivo (by calcium ionophore stimulated whole blood) in asthmatic subjects. We assessed the inhaled allergen induced airway responses of the early and late asthmatic response and changes in airway responsiveness.

\section{Methods}

SUBJECTS

Eleven non-smoking men with atopic asthma (mean age 28, range 19-44 years) with an $\mathrm{FEV}_{1}$ above $70 \%$ predicted were recruited (table). Subjects were having inhaled salbutamol only, apart from one who was also inhaling steroids and taking oral theophyllines. All subjects had been shown to have a dual asthmatic response to allergen on screening. None had had an upper respiratory tract infection or exacerbation of asthma 
within six weeks of starting the study. Nonsteroidal anti-inflammatory drugs were not allowed during the study period. The study was approved by the ethics committee of the National Heart and Lung Hospitals, and fully informed written consent was obtained from each subject.

Subjects had to be healthy at the physical examination and to have normal results in biochemical and haematological tests and a normal electrocardiogram before entry into the study. These were repeated during the study and at the end to assess the safety and tolerability of zileuton.

\section{STUDY PROTOCOL \\ Allergen challenge}

On a screening day the atopy of each subject was confirmed by obtaining a positive skinprick test response to either Dermatophagoides pteronyssinus or mixed grass pollen allergen extracts (Pharmacia, Milton Keynes) dissolved in normal saline. Subjects first inhaled the diluent, aerosolised with a Wright nebuliser (volume $2 \mathrm{ml}$, flow rate $7 \mathrm{l} / \mathrm{min}$, output $0.2 \mathrm{ml} / \mathrm{min}$ ), through a face mask with open mouthed tidal breathing for two minutes, and $\mathrm{FEV}_{1}$ was then measured for 15 minutes to exclude a bronchoconstrictor response to diluent. Cumulative doses of allergen were then inhaled in the same way to identify subjects with a dual asthmatic response. The initial allergen concentration used for inhalation was that which caused a $2-3 \mathrm{~mm}$ diameter weal in the skinprick test. Doubling concentrations of allergen were inhaled until an early asthmatic response (fall in $\mathrm{FEV}_{1}$ of at least $20 \%$ of the post-diluent value) was seen. No further allergen was then given, $\mathrm{FEV}_{1}$ was measured up to eight hours to detect any late asthmatic response, which was defined as a fall in $\mathrm{FEV}_{1}$ of at least $15 \%$ of post-diluent value. If a dual response was seen, the final allergen dose reached was used on the two allergen challenge study days. Of the 17 subjects screened, six subjects with an isolated early asthmatic response were not enrolled into the main study.

Two to three weeks later subjects returned for the first allergen challenge study. Zileuton $(800 \mathrm{mg}$ ) or matching placebo was ingested in the morning, and allergen challenge was performed three hours later. $\mathrm{FEV}_{1}$ was measured

Characteristics of the asthmatic subjects

\begin{tabular}{|c|c|c|c|c|}
\hline $\begin{array}{l}\text { Subject } \\
\text { No }\end{array}$ & $\begin{array}{l}\text { Age } \\
(y)\end{array}$ & $\begin{array}{l}F E V_{1} \\
l(\% \text { pred })\end{array}$ & $\begin{array}{l}P C_{20} \\
\text { methacholine } \\
(\mathrm{mg} / \mathrm{ml})\end{array}$ & Drugs† \\
\hline $\begin{array}{l}1 \\
2 \\
3 \\
4 \\
5 \\
6 \\
7 \\
8 \\
9\end{array}$ & $\begin{array}{l}22 \\
33 \\
21 \\
22 \\
24 \\
27 \\
27 \\
23 \\
29\end{array}$ & $\begin{array}{l}4 \cdot 9(98) \\
3 \cdot 0(81) \\
4 \cdot 9(117) \\
4 \cdot 1(98) \\
4 \cdot 8(117) \\
4 \cdot 3(100) \\
4 \cdot 6(105) \\
2 \cdot 6(84) \\
4 \cdot 6(112)\end{array}$ & $\begin{array}{l}0 \cdot 44 \\
0 \cdot 19 \\
0 \cdot 2 \\
0 \cdot 26 \\
3 \cdot 4 \\
0 \cdot 15 \\
1 \cdot 18 \\
0 \cdot 57 \\
1 \cdot 24\end{array}$ & $\begin{array}{l}\text { Salbutamol } \\
\text { Salbutamol } \\
\text { Salbutamol } \\
\text { Salbutamol } \\
\text { Salbutamol } \\
\text { Salbutamol } \\
\text { Salbutamol } \\
\text { Salbutamol } \\
\text { Salbutamol, beclomethasone, } \\
\text { theophylline }\end{array}$ \\
\hline
\end{tabular}

«The provocative dose of inhaled methacholine needed to cause a $20 \%$ fall in baseline $\mathrm{FEV}_{1}$. tInhaled, apart from the theophylline (oral) taken by subject 9 . every 10 minutes for the first hour after challenge, and then hourly for the next seven hours. At least two weeks later subjects returned for the second study to continue with an identical protocol provided that the baseline $\mathrm{FEV}_{1}$ was within $15 \%$ of that on the first study day. If not, they were asked to return for another study day.

$\mathrm{FEV}_{1}$ was measured with a dry bellow spirometer (Vitalograph, Buckingham) with the subject sitting upright. The mean of three good expiratory efforts was taken. Before each test subjects rested in a warm room for at least 15 minutes.

Non-specific airway responsiveness was assessed according to the method of Cockcroft et $a l^{22}$ on the day before and after each allergen test day, at the same time of the day for each subject. The provocative dose of methacholine needed to reduce $\mathrm{FEV}_{1}$ by $20 \%$ of the post-diluent value $\left(\mathrm{PC}_{20} \mathrm{FEV}_{1}\right)$ was determined. Methacholine was inhaled in the same way as allergen.

\section{Assessment of 5-lipoxygenase inhibition}

5-Lipoxygenase activity after allergen challenge was assessed by measuring urinary $\mathrm{LTE}_{4}$ excretion. ${ }^{23}$ Immediately before challenge subjects emptied their bladder and urine was then collected for four hours. Urine volume and $\mathrm{pH}$ were measured and aliquots of $30 \mathrm{ml}$ were stored at $-70^{\circ} \mathrm{C}$. $\mathrm{LTE}_{4}$ was extracted from the urine by reverse phase high performance liquid chromatography, tritiated $\mathrm{LTE}_{4}$ being used as an internal standard ${ }^{24}$ and measured by radioimmunoassay (Amersham International, Amersham). The efficacy of zileuton was also assessed by calcium ionophore stimulated whole blood $\mathrm{LTB}_{4}$ production ex vivo. Three and a half, four, five, seven, nine, and 10 hours after it was given $5 \mathrm{ml}$ of whole blood was incubated with $5 \mu \mathrm{l}$ of $50 \mathrm{mM}$ calcium ionophore for $15 \mathrm{~min}$ utes and centrifuged, and the supernatant was stored at $-70^{\circ} \mathrm{C}$. $\mathrm{LTB}_{4}$ was extracted by high performance liquid chromatography, and assayed by radioimmunoassay.

\section{Drug level}

Plasma level of drug was measured at 3.5, 4 and 5 hours post-dose on both placebo and active days. Zileuton was extracted by high performance liquid chromatography and measured by ultraviolet absorbance as developed by Abbott Laboratories.

\section{ANALYSIS}

$\mathrm{PC}_{20}$ values were log transformed before analysis. $\mathrm{FEV}_{1}$ and $\mathrm{PC}_{20}$ values were compared by analysis of variance. Paired data were analysed by the Wilcoxon sign rank test and the relation between two variables by regression analysis. Results are presented as means with the standard errors of the mean in parentheses unless otherwise stated. $p<0.05$ was accepted as significant.

\section{Results}

SUBJECTS

Of the 11 subjects who showed a late response 


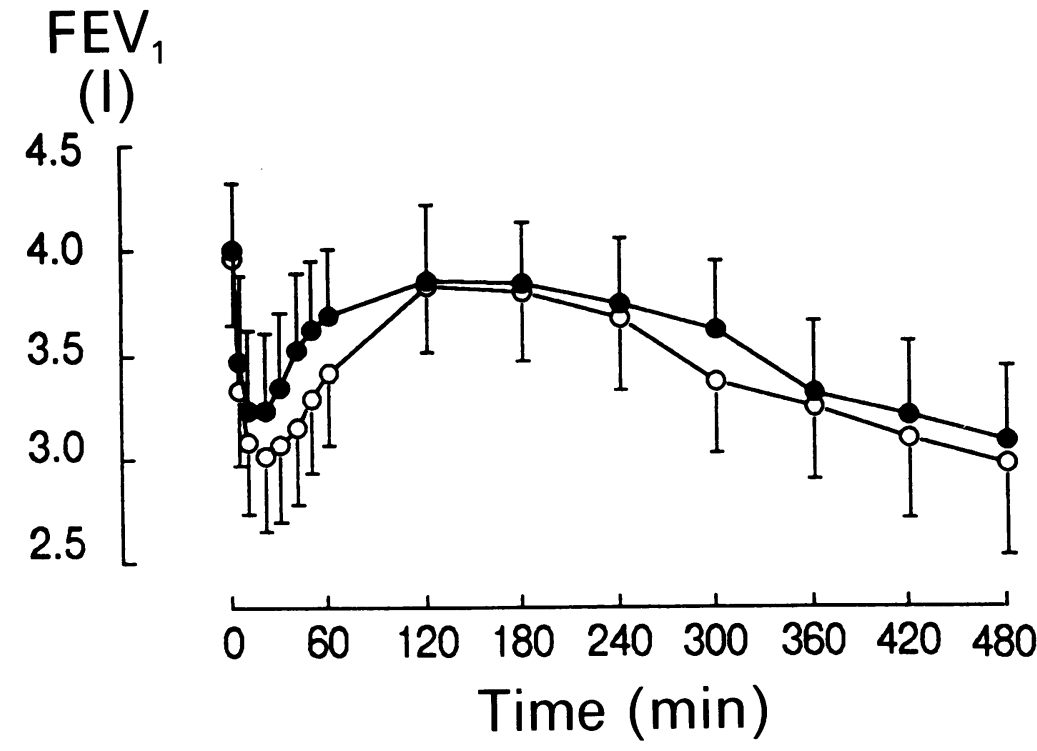

Figure 1 Effect of zileuton ( $800 \mathrm{mg}$ orally) on early and late asthmatic responses after allergen challenge. Zileuton; $\bigcirc$ placebo. Values are means with 1 SEM.

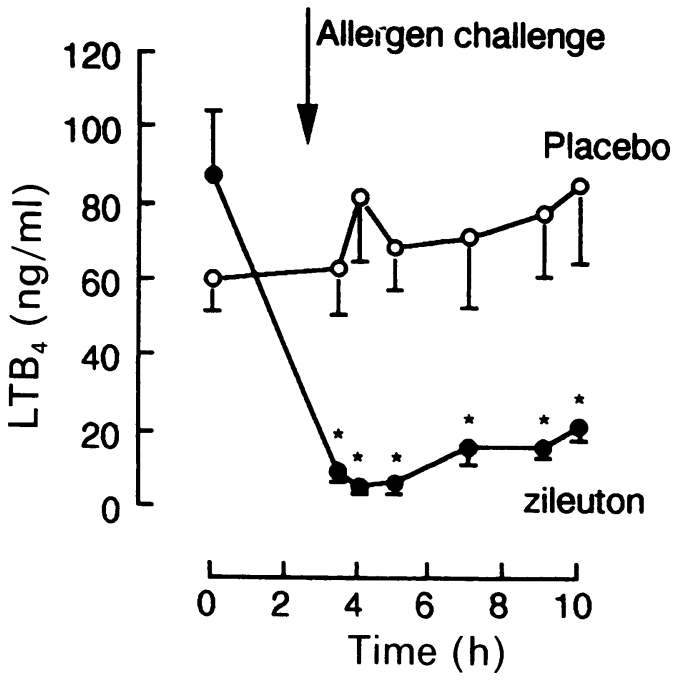

Figure 3 Time course of effect of zileuton on calcium ionophore stimulated whole blood leukotriene $(L T) B_{4}$ production. Values are means with 1 SEM. ${ }^{\star} p<0.005$.

was found by two way analysis according the the method of Hills and Armitage. ${ }^{25}$ There was a trend for the fall in $\mathrm{FEV}_{1}$ during the early asthmatic response to be less with zileuton, but this did not reach statistical significance at any point (maximum fall in $\mathrm{FEV}_{1}$ : placebo 1.08 $(0.25) 1$, zileuton $0.83(0.21) 1 ; p=0 \cdot 18)$. The maximum difference between placebo and zileuton was 40 minutes after allergen challenge, which is after the nadir of the fall in $\mathrm{FEV}_{1}$ (fig 1; difference in $\mathrm{FEV}_{1}-0.33(0 \cdot 16)$ 1; $\mathrm{p}=0.08)$. There was no difference between placebo and zileuton in the late asthmatic response (maximum fall in $\mathrm{FEV}_{1}$ : placebo $1 \cdot 16$ $(0.24) 1$, zileuton $0.92(0.27) 1 ; \mathrm{p}=0.22)$. There were no significant differences in the areas under the curve during the early or late phases. (b)

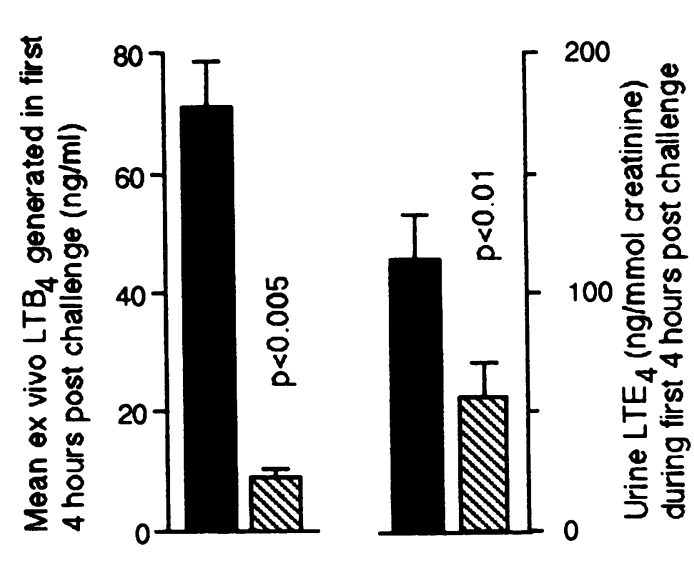

Figure 2 Effect of zileuton on airway responsiveness to inhaled methacholine before and after allergen challenge. $P C_{20} F E V$ is the provocative dose $(\mathrm{mg} / \mathrm{ml})$ of inhaled methacholine needed to cause a fall in $F E V$, of $20 \%$ of methacholine needed to cause a fall in FEV, of $20 \%$ of
the post-diluent value, and individual values for each subject before and after allergen challenge are shown. The geometric mean and $95 \%$ confidence interval for each day are also shown.

Figure 4 Effect of zileuton ( $)$ and placebo ( $\square$ ) on (a) mean ex vivo leukotriene ( $L T$ ) $B_{4}$ production and (b) urine $L T E_{4}$. Mean ex vivo $L T B_{4}$ production refers to mean whole blood calcium ionophore stimulated $L T B_{4}$ production for four hours after allergen challenge. Urine $L T E_{4}$ is the total urinary excretion of $L T E_{4}$ over four hours. Values are means with 1 SEM. 
Figure 5 Scatter

diagrams showing the linear regression

relationships between

zileuton induced change in

maximum fall in FEV,

during the early asthmatic

response ( $E A R)$ and

reduction in urinary

leukotriene $(L T) E_{+}$

production. (a)

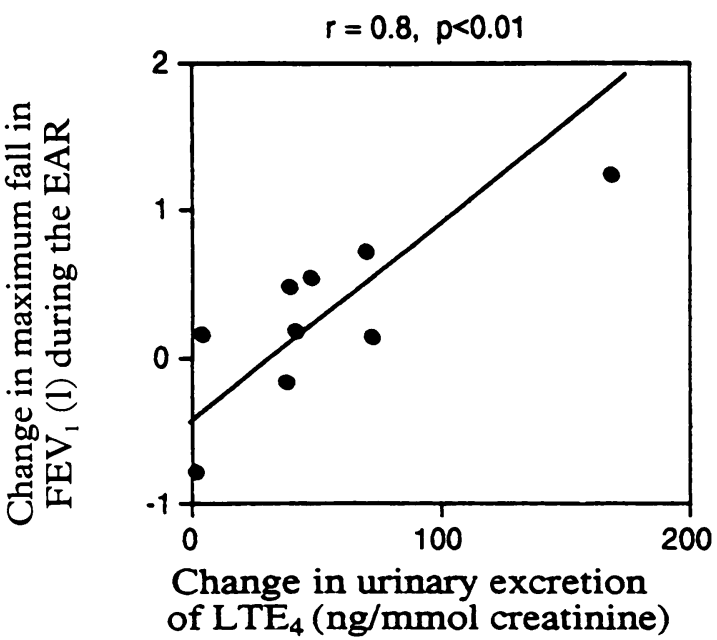

(b)

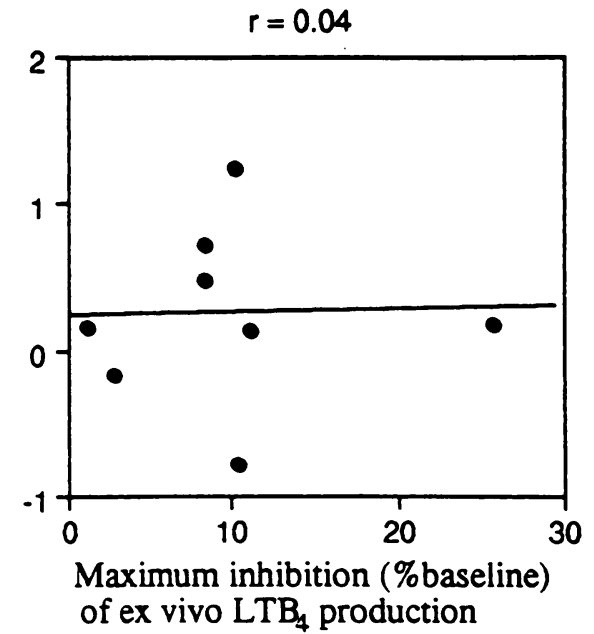

Baseline airway responses to inhaled metacholine before allergen challenge were very similar for placebo and zileuton (geometric mean $\mathrm{PC}_{20} \quad \mathrm{FEV}_{1}=0.41 \quad(95 \%$ confidence interval $0 \cdot 20-0.84)$ and $0.44 \mathrm{mg} / \mathrm{ml}(0 \cdot 15-$ $0 \cdot 78$ ). The increase in airway responsiveness after allergen challenge did not differ significantly after placebo and zileuton treatment (before/after challenge $\mathrm{PC}_{20} \mathrm{FEV}_{1}$ metacholine: placebo $2 \cdot 13$, zileuton $1 \cdot 89$; fig 2 ).

\section{EFFECTS ON IN VIVO AND EX VIVO LEUKOTRIENE GENERATION}

Zileuton substantially inhibited calcium ionophore stimulated whole blood $\mathrm{LTB}_{4}$ production with maximum inhibition $(93.1 \%$ of baseline; $\mathrm{p}<0.005)$ four hours post-dose; after the dose had been given significant inhibition was still present at 10 hours after the dose $(63.5 \%$ of baseline; $p<0.005$; fig 3$)$. Mean urinary $\mathrm{LTE}_{4}$ excretion after allergen challenge was reduced by about half by zileuton treatment (placebo 111.5 (23.5), zileuton $58.2(14.8) \mathrm{ng} / \mathrm{mmol}$ creatinine; $\mathrm{p}<0.01$; fig 4).

The zileuton induced change in maximum fall in $\mathrm{FEV}_{1}$ for the early asthmatic response correlated with the reduction in urinary $\mathrm{LTE}_{4}$ production $(r=0.8, p<0.01$; fig 5$)$ but not with the inhibition of calcium ionophore stimulated whole blood $\mathrm{LTB}_{4}$ production $(\mathrm{r}=0.04, \mathrm{p}>0.5)$.

\section{PLASMA ZILEUTON CONCENTRATIONS}

Mean plasma zileuton concentrations three and a half, four, and five hours after ingestion were $3.37(0.36), 3.03(0.39)$ and $2.6(0.27) \mu \mathrm{g} / \mathrm{ml}$ respectively on the days of zileuton treatment; no drug was detected on the placebo day. There was no relation between the peak drug concentrations and change in $\mathrm{FEV}_{1}$ during the early and late asthmatic responses, reduction in urinary $\mathrm{LTE}_{4}$ excretion, or calcium ionophore stimulated whole blood $\mathrm{LTB}_{4}$ production.

\section{Discussion}

We found that zileuton at the dose used in the study partially reduced urinary $\mathrm{LTE}_{4}$ excretion and substantially reduced calcium ionophore stimulated whole blood $\mathrm{LTB}_{4}$ production ex vivo. There was a trend towards a reduction in the fall in $\mathrm{FEV}_{1}$ during the early asthmatic response with zileuton, but neither this nor the late asthmatic response or increase in airway responsiveness differed significantly between zileuton and placebo. The change in the early asthmatic response induced by zileuton correlated with the change in urinary $\mathrm{LTE}_{4}$ concentrations but not with the change in ex vivo $\mathrm{LTB}_{4}$ production.

In vivo activation of the 5-lipoxygenase pathway in asthmatic patients during an asthmatic attack has been shown by the increased urinary excretion of $\mathrm{LTE}_{4}{ }^{23}$ and by increased concentrations of cysteinyl leukotrienes in bronchoalveolar lavage fluid recovered by fibreoptic bronchoscopy during the early ${ }^{26}$ and late ${ }^{27}$ responses to inhaled allergen challenge. In the present study the activation of 5lipoxygenase in airways was assessed by urinary excretion of $\mathrm{LTE}_{4}$ as this is simple and non-invasive and did not interfere with measurements of lung function. Urinary $\mathrm{LTE}_{4}$ excretion after allergen challenge is likely to reflect airway leukotriene generation, as there was no evidence of systemic effects in any subjects. Zileuton reduced the urinary excretion of $\mathrm{LTE}_{4}$ by about half, though not down to the range found in non-asthmatic subjects in this laboratory. ${ }^{23}$ This suggests that 5-lipoxygenase activity was only partially inhibited, and may explain the non-significant reduction in bronchoconstriction during the early asthmatic response. A significant reduction of airway response to allergen may be seen only if more complete inhibition of leukotrienes generation can be achieved, as the leukotrienes are very potent biological agents: the cysteinyl leukotrienes are thousands of times more potent than histamine in causing bronchoconstriction, ${ }^{28}$ and $\mathrm{LTB}_{4}$ is one of the most potent chemotactic agents known. ${ }^{29}$

The early bronchoconstrictor response after allergen challenge is thought to be due to release of mediators, such as histamine and leukotrienes, from inflammatory cells via IgE mediated mechanisms. Although not statis- 
tically significant, the maximum reduction of the fall in $\mathrm{FEV}_{1}$ produced by zileuton was after the nadir in the fall in $F E V_{1}$ following allergen challenge. This time course of action is consistent with the known action of leukotrienes and histamine, inhaled cysteinyl leukotrienes causing maximum bronchoconstriction at about 15 minutes, ${ }^{4-6}$ and histamine somewhat earlier. Leukotrienes are not stored by resting cells (unlike histamine), and are generated only after stimulation, so they would be expected to contribute more to the latter part of the early bronchoconstrictor response after allergen challenge. In a study by Britton and coworkers, in which a leukotriene antagonist, L649923, reduced the early response to allergen, the maximum effect was seen after the nadir of the early asthmatic response.$^{11}$ In another study an antihistamine was effective in the first $15 \mathrm{~min}$ utes of the early asthmatic response after allergen challenge. ${ }^{30}$ The significant correlation between inhibition of in vivo $\mathrm{LTE}_{4}$ generation and reduction in early asthmatic response also supports the role of the leukotrienes as mediators in the early asthmatic response. Although the pattern of change in the early asthmatic response is similar to that in the study of Britton et al, ${ }^{11}$ the lack of statistical significance in our study may be due to a type II error.

Although leukotriene production has been shown during the late asthmatic response following allergen challenge, ${ }^{27}$ zileuton did not reduce the late fall in $\mathrm{FEV}_{1}$ significantly in the present study. This may be because the activity of zileuton in the single dose of $800 \mathrm{mg}$ used in this study may have been insufficient by that time, particularly when it was only partially effective during the early phase as measured by urinary $\mathrm{LTE}_{4}$ levels. In two patients where serum drug concentrations seven hours after the dose were available little zileuton was detected.

Previous studies of 5-lipoxygenase inhibitors in man have depended on ex vivo methods of assessing its activity. In the present study zileuton was more effective in inhibiting ex vivo calcium ionophore stimulated whole blood $\mathrm{LTB}_{4}$ production than in inhibiting leukotriene production in vivo as reflected by urinary $\mathrm{LTE}_{4}$ excretion, and there was no correlation between these two variables. There are several possible explanations. The lesser effect in vivo may be due to inadequate penetration of zileuton into airway tissues, or a higher plasma concentration may be needed to suppress airways 5-lipoxygenase adequately. Alternatively, different inflammatory cells may have different susceptibilities to the effect of zileuton, such that the mast cells, macrophages, or eosinophils in the airways may not have been affected as much as neutrophils in the peripheral blood. In addition, the cellular generation of the cysteinyl leukotrienes may be less affected than that of $\mathrm{LTB}_{4}$. The lack of relation between the changes in leukotriene generation ex vivo and the early asthmatic response suggest that this is not a useful method for assessing the clinical efficacy of 5-lipoxygenase inhibitors in man.

In this study a single oral dose $(800 \mathrm{mg})$ of zileuton was only partially effective in inhibiting activation of 5-lipoxygenase in vivo by inhaled allergen despite near complete ex vivo inhibitory activity. There was a trend towards a reduction in the early asthmatic bronchoconstrictor response but this was not significant. Measurement of leukotriene production in vivo rather than ex vivo may be more useful in future studies of 5-lipoxygenase inhibitors in man. Our results would fit a role for the leukotrienes in the early asthmatic response to inhaled allergen, particularly if inhibition of leukotriene related airway responses requires near complete inhibition of the 5-lipoxygenase enzyme in vivo. Further studies with higher or repeated doses of zileuton or with more potent 5-lipoxygenase inhibitors in man are needed.

1 Samuelsson B. Leukotrienes: mediators of immediate hypersensitivity reactions and inflammation. Science 1983; 220:568-75.

2 Hannarström S. Leukotrienes. Ann Rev Biochem 1983; 52:355-77.

3 Drazen JM, Austen KF. Leukotrienes and airway responses. Am Rev Respir Dis 1987;136:985-8.

4 Barnes NC, Piper PJ, Costello JF. Comparative effects of inhaled leukotriene $\mathrm{C}_{4}$, leukotriene $\mathrm{D}_{4}$, and histamine in normal human subjects. Thorax 1984;39:500-4.

5 Adelroth E, Morris MM, Hargreave FE, O'Byrne PM. Airway responsiveness to leukotrienes $C_{4}$ and $D_{4}$ and to methacholine in patients with asthma and normal controls. N Engl J Med 1986;315:480-4.

6 Davidson AB, Lee TH, Scanlon PD, et al. Bronchoconstrictor effects of leukotriene $E_{4}$ in normal and asthmatic subjects. Am Rev Respir Dis 1987;135:333-7.

7 Arm JA, Spur BW, Lee TH. The effects of inhaled leukotriene $\mathrm{E}_{4}$ on the airway responsiveness to histamine in subjects with asthma and normal subjects. J Allergy Clin Immunol 1988;82:654-60.

8 Ford-Hutchinson AW, Bray MA, Doig MV, Shipley ME, Smith MJH. Leukotriene B, a potent chemokinetic and aggregating substance from polymorphonuclear leukocytes. Nature 1980;286:264-5.

9 Marom S, Shelhamer JH, Bach MK, Morton DR, Kaliner $M$. Slow reacting substances leukotrienes $C_{4}$ and $D_{4}$ increase the release of mucus from human airways in vitro. Am Rev Resp Dis 1982;126:449-51.

10 Evans TW, Rogers DF, Aursudkig B, Chung KF, Barnes PJ. Regional and time-dependent effects of inflammatory mediators on airway microvascular permeability in the mediators on airway microvascular
guinea pig. Cli Sci 1989;76:161-6.

11 Britton JR, Hanley SP, Tattersfield AE. The effect of an oral leukotriene D4 antagonist L649,923 on the response to inhaled antigen in asthma. J Allergy Clin Immunol 1987;79:811-6.

12 Fuller RW, Black PN, Dollery CT. Effects of the oral leukotriene $D_{4}$ antagonist $L Y 171883$ on inhaled and intradermal antigen and $\mathrm{LTD}_{4}$ in atopic subjects. J Clin Allergy Immunol 1989;83:939-44.

13 Israel I, Juniper EF, Callaghan JT, et al. Effect of a leukotriene antagonist, LY 171883, on cold air-induced bronchoconstriction in asthmatics. Am Rev Respir Dis 1989;140:1348-53.

14 Kruetner W, Sherwood J, Sehring S, et al. Antiallergic activity of Sch 37224 , a new inhibitor of leukotriene formation. J Pharmacol Exp Ther 1988;247:997-1003.

15 Johnson HG, Stout BK. Activity of a novel hydroquinone inhibitor of leukotriene synthesis (U-66,858) in the rhesus monkey Ascaris reactor. Int Arch Allergy Appl Immunol 1988;87:204-7.

16 Ku EC, Raychaudhuri A, Ghai G, et al. Characterisation of CGS 8515 as a selective 5-lipoxygenase inhibitor using in vitro and in vivo models. Biochim Biophys Acta 1988; vitro and in

17 Mann JS, Holgate ST. Effect of piriprost (U-60257), a novel lipoxygenase inhibitor, on allergen and exercise induced asthma. Thorax 1986;41:746-52.

18 Fuller RW, Maltby N, Richmond R, et al. Oral nafazatrom in man: effect on inhaled antigen challenge. $\mathrm{Br} J \mathrm{Clin}$ Pharmacol 1987;23:677-81.

19 Carter GW, Young PR, Albert D, et al. Development of A64077 , a promising agent for the treatment of leukotrienemediated diseases [abstract]. In: Proceedings of the 7 th International Conference on Prostaglandins and Related International Conference
Compounds. 1990:192.

20 Summers JB, Gunn BP, Martin JG, et al. Structure-activity 
analysis of a class of orally active hydroxamic acid inhibitors of leukotriene biosynthesis. J Med Chem 1988;31:1960-4.

21 Malo PE, Wiley YD, Shaughnessy TK, Bell R, Summers JB, Brooks DW, Carter GW. Inhibition of antigeninduced contractions of guinea-pig tracheal strips (GPTS) by lipoxygenase (5-LO) inhibitors [abstract]. Am Rev Respir Dis 1988;139(suppl):A92.

22 Cockcroft DW, Killian DN, Mellon JJA, Hargreave FE. Bronchial reactivity to inhaled histamine: a method and Bronchial reactivity to inhaled histamine:
clinical survey. Clin Allergy 1977;7:235-43.

23 Taylor GW, Taylor I, Black P, et al. Urinary leukotriene $E_{4}$ after antigen challenge and in acute asthma and allergic rhinitis. Lancet 1989;i:584-8.

24 Richmond RR, Turner NC, Maltby NH, et al. Single step procedure for the extraction and purification of leukotrienes $B_{4}, C_{4}$ and D $J$ Chromatology 1987;417:241-51.

25 Hills $\mathrm{M}$, Armitage $\mathrm{P}$, The two-period cross-over trial. $\mathrm{Br} \mathrm{J}$
Clin Pharmacol 1979;5:7-20.

26 Chan-Yeung $M$, Chan $H$, Tse KS, Salari H, Lam S. Histamine and leukotrienes release in bronchoalveolar fluid during plicatic acid-induced bronchoconstriction. $J$ Allergy Clin Immunol 1989;84:762-8.

27 Dias P, Gonzalez MC, Galleguillos FR, et al. Leukocytes and mediators in bronchoalveolar lavage during allergeninduced late phase reactions. Am Rev Respir Dis 1989;139:1383-9.

28 Dahlén SE, Hedqvist $P$, Hammarström S, Samuelsson $B$. Leukotrienes are potent constrictors of human bronchi. Nature 1980;288:484-6.

29 Bray MA. The pharmacology and pathophysiology of leukotriene $B_{4}$. Br Med Bull 1983;39:249-54

30 Rafferty $\mathrm{R}, \mathrm{Ng}$ WH, Phillips $\mathrm{G}$, et al. The inhibitory actions of azelastine hydrochloride on the early and late bronchoconstrictor responses to inhaled allergen in atopic asthma. J Allergy Clin Immunol 1989;84:649-57. 